\title{
COMMENTARY
}

\section{Pitfalls in haemodynamic monitoring based on the arterial pressure waveform}

\author{
Luigi Camporota and Richard Beale* \\ See related research of Eleftheriadis et al., http://ccforum.com/content/13/6/R179
}

\begin{abstract}
The accuracy of the arterial pressure-based cardiac output FloTrac-Vigileo system remains unacceptably low during haemodynamic instability. Data show that the measurement of cardiac output (CO) is strongly influenced by changes in factors that affect arterial blood pressure (ABP) - for example, vascular tone and compliance and the arterial site - independently of true changes in CO. Although in theory the autocalibration algorithm of FloTrac-Vigileo should adjust for those changes, the model undercompensates (or overcompensates) for prominent increases (or decreases) in vascular tone and compliance, making the system largely dependent on changes in ABP. These limitations make FloTrac-Vigileo accurate in stable haemodynamic conditions only, and until more robust algorithms and further validation studies become available, we should be aware that during haemodynamic instability or in extreme conditions of vasodilation or vasoconstriction, the measured CO may diverge from an independent bolus indicator dilution measurement, particularly if a peripheral artery is used. In these conditions, we advocate the use of transpulmonary indicator dilution via a femoral artery.
\end{abstract}

In recent years, there has been a trend toward the use, in intensive care units (ICUs) and in operating theatres, of 'minimally invasive' haemodynamic monitoring systems for the continuous measurement of cardiac output (CO). In this context, 'minimally invasive' has come to mean 'less invasive than a pulmonary artery catheter' and is arguably an unhelpful term. Nevertheless, among the available devices, the FloTrac-Vigileo system (FTV) (Edwards

*Correspondence: richard.beale@gstt.nhs.uk

Department of Adult Critical Care - Guy's and St Thomas' NHS Foundation Trust, St Thomas' Hospital, 1st Floor East Wing - Lambeth Palace Road, London, SE1 7EH, UK
Lifesciences LLC, Irvine, CA, USA) does perhaps deserve this epithet as it is designed to run from any arterial line (frequently present in patients in the ICU or undergoing major surgery, at least in Europe) and requires no calibration. This latter capability is a consequence of a sophisticated algorithm that the device employs to analyse the arterial pressure waveform (APW), whether obtained from the radial or the femoral artery, to determine the presumed non-linear proportionality between arterial blood pressure (ABP) and stroke volume (SV) and hence give an estimate of $\mathrm{CO}$. However, despite its simplicity of use, the reliability of this system is uncertain during conditions of haemodynamic instability, when the dose of vasopressors changes rapidly but having an accurate $\mathrm{CO}$ is essential to guide appropriate management.

The FloTrac algorithm analyses the statistical distribution of data points of the ABP sampled at $100 \mathrm{~Hz}$ and is based on the principle that aortic pulse pressure is proportional to SV, measured as the standard deviation of the arterial pressure $\left(\sigma_{\mathrm{AP}}\right)$ around the mean arterial pressure (MAP). $\sigma_{\mathrm{AP}}$ is then multiplied by a scaling parameter derived by a multivariate polynomial equation that includes the patient's demographic data, arterial compliance, skewness (symmetry of the waveform) to adjust for vascular tone, and kurtosis (measure of how peaked the APW is) to compensate for the differences in APW due to arterial site.

The fundamental problem with this approach is to be sure that it can identify and accurately represent those situations in which a change in blood pressure (systolic, diastolic, mean and pulse pressures) is associated with a change in SV that is directionally inverse as opposed to directionally similar. In other words, the system should be able to distinguish blood pressure changes due to volume loading manoeuvres, in which the primary intervention is aimed at increasing $\mathrm{CO}$, and so blood pressure will usually change only if this occurs, and in the same direction, although the relative sensitivity of the manner in which the two variables respond can of course be quite different. When the primary change is in arterial resistance, as when a vasopressor is deployed, the situation is 
more challenging since the intervention is aimed at generating a blood pressure increase, but the effect upon SV may be in either direction. This is the situation that is most testing for arterial pressure-derived $\mathrm{CO}$ algorithms, especially if uncalibrated.

In a previous issue of Critical Care, Eleftheriadis and colleagues [1], who had observed implausible changes in $\mathrm{CO}$ when vasopressors were employed in their clinical practice, reported a simple but elegant experiment that shows that, in patients undergoing coronary artery bypass grafting, variations in $\mathrm{ABP}$ in response to a stepwise change in noradrenaline lead to parallel changes in CO measured by the second-generation FTV (software version 1.14), which were not present when $\mathrm{CO}$ was measured conventionally using a thermodilution pulmonary artery catheter. During these conditions of pharmacologically driven changes in vascular tone, the bias and the limits of agreement of the FTV CO were unacceptably high compared with thermodilution, and furthermore, the divergence in $\mathrm{CO}$ obtained by the two methods became greater with each step increase in ABP, demonstrating that (at least in this context) the $\mathrm{CO}$ measured by FTV was dependent on MAP.

These findings highlight the fact that arterial pressurebased cardiac output (APCO) methods, particularly when uncalibrated, are still strongly influenced by factors that affect ABP and APW independently of SV and CO. The quality of the APW, the degree of the pressure wave reflection at the arterial site (that is, radial versus femoral), the degree and rapidity of change of vascular tone and compliance, and the geometry of the arterial system can all affect APCO algorithms, making these systems unreliable in patients undergoing rapid changes in ABP due to change in vascular resistance (for example, during pharmacologically induced vasoconstriction). So although theoretically the algorithm should compensate for changes in tone and arterial site every 60 seconds in accordance with the model, it seems clear that the autocalibration scaling factor undercompensates for the increase in vascular tone and overcompensates in conditions of low vascular tone, making the system directly proportional to changes in ABP.

In fairness, the second-generation software of FTV has shown improved accuracy and precision in conditions of haemodynamic stability, or during changes in intravascular volume in the absence of significant variation in vascular tone, and so may be helpful in guiding volume loading (for example, during 'early goal-directed therapy' or pre-operative optimisation for elective surgery). However, unacceptably poor agreement has been shown in studies including patients at extremes of vascular tone and compliance such as cirrhotic patients undergoing liver transplant [2,3], patients with septic shock [4], haemodynamically unstable critically ill patients on large doses of vasopressors [5], and patients undergoing cardiac surgery [6], in which changes in vascular tone and compliance are prominent and the apparent changes in $\mathrm{CO}$ are due to the variations in the APW [7].

Another important factor to consider when interpreting $\mathrm{CO}$ measured by any APCO system is that the site of ABP measurement (for example, radial versus femoral artery) may significantly affect the APW and therefore CO. Discrepancies between central and peripheral blood pressures have been described in a number of clinical circumstances such as after cardiopulmonary bypass [8], during deep hypothermic circulatory arrest [9], during cardiopulmonary resuscitation [10], in patients with septic shock treated with high-dose vasoconstrictors [11], and in patients during reperfusion after liver transplant [12]. The differences in ABP between different sites may be large and in conditions of intense vasoconstriction the radial ABP may underestimate the true aortic $\mathrm{ABP}$, giving a falsely low $\mathrm{CO}$ value. It is concerning that in the study by Eleftheriadis and colleagues [1], the large differences in $\mathrm{CO}$ between FTV and pulmonary artery catheter were demonstrated despite the fact that the ABP for the FTV was obtained from the femoral artery. Central arteries should be less sensitive to variations in response to vasoactive drugs as the arteriolar tone is already high, and the reflection coefficient (the ratio between the reflected wave and the incident wave in the frequency domain) can be increased only marginally by intense vasoconstriction [13]. Studies looking at the differences in $\mathrm{CO}$ when the FTV was connected to a radial or a femoral artery have shown variable results $[14,15]$ but highlight the fact that the impact of the site of the arterial catheter may not be negligible and the algorithm may not be able to compensate for changes in shape and amplitude of the APW in extreme haemodynamic conditions.

In conclusion, autocalibrated systems are useful only when used to monitor changes in SV during fluid challenge in stable conditions but become less accurate with changes in vascular tone and reactivity. Until more robust algorithms and further validation studies in critically ill patients become available, we should be aware that in conditions of haemodynamic instability, uncalibrated $\mathrm{ABP} \mathrm{CO}$ systems may diverge from independent bolus measurements, particularly if a peripheral artery is used as this may underestimate or overestimate central blood pressure depending on the vascular tone. In these conditions, we advocate the use of systems that are recalibrated frequently using indicator dilution via either the femoral or the pulmonary artery.

\footnotetext{
Abbreviations

$\sigma_{A P}=$ arterial pressure; $\mathrm{ABP}=$ arterial blood pressure; $\mathrm{APCO}=$ arterial pressurebased cardiac output; APW = arterial pressure waveform; $C O=$ cardiac output FTV = FloTrac-Vigileo system; ICU = intensive care unit; MAP = mean arterial pressure; SV = stroke volume.
} 


\section{Competing interests}

$\mathrm{RB}$ and $\mathrm{LC}$ declare that they have no personal competing interests. The Department has received research support from Philips (Amsterdam, The Netherlands), LiDCO (Cambridge, UK), Applied Physiology (Sydney, Australia), Covidien (Dublin, Ireland), and Oxford Biosignals (Carmel, IN, USA).

Published: 5 March 2010

\section{References}

1. Eleftheriadis S, Galatoudis Z, Didilis V, Bougioukas I, Schon J, Heinze H, Berger $\mathrm{KU}$, Heringlake $\mathrm{M}$ : Variations in arterial blood pressure are associated with parallel changes in FlowTrac/Vigileo(R)-derived cardiac output measurements: a prospective comparison study. Crit Care 2009, 13:R179.

2. Biancofiore G, Critchley LA, Lee A, Bindi L, Bisà M, Esposito M, Meacci L, Mozzo R, DeSimone P, Urbani L, Filipponi F: Evaluation of an uncalibrated arterial pulse contour cardiac output monitoring system in cirrhotic patients undergoing liver surgery. Br J Anaesth 2009, 102:47-54.

3. Biais M, Nouette-Gaulain K, Cottenceau V, Vallet A, Cochard JF, Revel P, Sztark F: Cardiac output measurement in patients undergoing liver transplantation: pulmonary artery catheter versus uncalibrated arterial pressure waveform analysis. Anesth Analg 2008, 106:1480-1486, table of contents.

4. Sakka SG, Kozieras J, Thuemer O, van Hout N: Measurement of cardiac output: a comparison between transpulmonary thermodilution and uncalibrated pulse contour analysis. Br J Anaesth 2007, 99:337-342.

5. Compton FD, Zukunft B, Hoffmann C, ZidekW, Schaefer JH: Performance of a minimally invasive uncalibrated cardiac output monitoring system (Flotrac/Vigileo) in haemodynamically unstable patients. Br J Anaesth 2008, 100:451-456.

6. Mayer J, Boldt J, Schollhorn T, Rohm KD, Mengistu AM, Suttner S: Semiinvasive monitoring of cardiac output by a new device using arterial pressure waveform analysis: a comparison with intermittent pulmonary artery thermodilution in patients undergoing cardiac surgery. $\mathrm{Br} J$ Anaesth 2007, 98:176-182.

7. Mayer J, Boldt J, Poland R, Peterson A, Manecke GR Jr.: Continuous arterial pressure waveform-based cardiac output using the FloTrac/Vigileo: a review and meta-analysis. J Cardiothorac Vasc Anesth 2009, 23:401-406.
8. Chauhan S, Saxena N, Mehrotra S, Rao BH, Sahu M: Femoral artery pressures are more reliable than radial artery pressures on initiation of cardiopulmonary bypass. J Cardiothorac Vasc Anesth 2000, 14:274-276.

9. Manecke GR Jr., Parimucha M, Stratmann G, Wilson WC, Roth DM, Auger WR, Kerr KM, Jamieson SW, Kapelanski DP, Mitchell MM: Deep hypothermic circulatory arrest and the femoral-to-radial arterial pressure gradient. $J$ Cardiothorac Vasc Anesth 2004, 18:175-179.

10. Rivers EP, Lozon J, Enriquez E, Havstad SV, Martin GB, Lewandowski CA, Goetting MG, Rosenberg JA, Paradis NA, Nowak RM: Simultaneous radial, femoral, and aortic arterial pressures during human cardiopulmonary resuscitation. Crit Care Med 1993, 21:878-883.

11. Dorman T, Breslow MJ, Lipsett PA, Rosenberg JM, Balser JR, Almog Y, Rosenfeld BA: Radial artery pressure monitoring underestimates central arterial pressure during vasopressor therapy in critically ill surgical patients. Crit Care Med 1998, 26:1646-1649.

12. Arnal D, Garutti I, Perez-Pena J, Olmedilla L, Tzenkov IG: Radial to femoral arterial blood pressure differences during liver transplantation. Anaesthesia 2005, 60:766-771.

13. Nichols WW, O'Rourke MF: MCDonald's Blood Flow in Arteries: Theoretical, Experimental and Clinical Principles. 5th edition. London: Hodder Arnold; 2005

14. Hofer CK, Button D, Weibel L, Genoni M, Zollinger A: Uncalibrated radial and femoral arterial pressure waveform analysis for continuous cardiac output measurement: an evaluation in cardiac surgery patients. $J$ Cardiothorac Vasc Anesth 2009 Aug 21. [Epub ahead of print].

15. Schramm S, Albrecht E, Frascarolo P, Chassot PG, Spahn DR: Validity of an arterial pressure waveform analysis device: does the puncture site play a role in the agreement with intermittent pulmonary catheter thermodilution measurements? J Cardiothorac Vasc Anesth 2009 Aug 21. [Epub ahead of print].

doi:10.1186/cc8845

Cite this article as: Camporota L, Beale R: Pitfalls in haemodynamic monitoring based on the arterial pressure waveform. Critical Care 2010, 14:124. 